\title{
Are goblet cell carcinoids a group of heterogeneous tumors?
}

\author{
Jirka Macaka,c, Kristina Nemejcova ${ }^{\mathrm{b}}$, Jana Dvorackovaa,c
}

\begin{abstract}
Background. Goblet cell carcinoids belong to neuroendocrine tumors, according to the WHO classification. The tumors are diagnosed based on a typical histological pattern and using neuroendocrine markers. However, some tumors do not react with these markers and yet expression of proliferative markers is high. Do these tumors belong to G1 and G2 neuroendocrine tumors?

Methods. The sample comprised nine cases of tumors of the appendix identified by immunohistological methods as goblet cell carcinoids or adenocarcinoma ex goblet cell carcinoid.

Results. In six cases, hematoxylin and eosin staining revealed tumors completely or $90 \%$ made of characteristic large tumor cells observed in typical goblet cell carcinoids. The remaining three cases were identified as adenocarcinomas arising ex goblet cell carcinoids. Immunohistological examination revealed that in four cases of typical goblet cell carcinoids, expression of neuroendocrine markers was low or completely negative. Yet in two cases, the Ki-67 proliferative index exceeded the $20 \%$ cut-off for inclusion in the G1 and G2 category.

Conclusions. Goblet cell carcinoids are a heterogeneous group of tumors that may express neuroendocrine markers in a small number of tumor cells or are negative to these markers. However, high expression of the proliferative marker $\mathrm{Ki}-67$ exceeds the criteria for $\mathrm{G} 1$ and G2 neuroendocrine tumors. It is our opinion that these tumors may be classified as a specific type of carcinoma.
\end{abstract}

Key words: goblet cell carcinoid, appendix, immunohistology, negative neuroendocrine markers

Received: January 19, 2017; Accepted: May 19, 2017; Available online: June 12, 2017

https://doi.org/10.5507/bp.2017.027

${ }^{a}$ Department of Pathology, University of Ostrava and University Hospital Ostrava, Czech Republic

${ }^{b}$ Department of Pathology, $1^{\text {st }}$ Faculty of Medicine, Charles University and General University Hospital, Prague, Czech Republic 'CGB Laboratory Inc., Ostrava, Czech Republic

Corresponding author: Jiri Macak, e-mail: macak.jirka@seznam.cz

\section{INTRODUCTION}

Tumors referred to as goblet cell carcinoids (GCCs) are uncommon ${ }^{1-3}$. They are made of large cells. The cytoplasm is filled with mucin, the nuclei are pushed to the periphery under the cell membrane. Mucin production has always been thought to be related to adenocarcinomas but mucin has also been demonstrated in carcinoids ${ }^{4-6}$. Gagné et al. ${ }^{7}$ described three tumors of the appendix considered to be a transitional type between carcinoid and adenocarcinoma. Höfler et al..$^{8}$ reported production of mucins and 5-hydroxytryptamine in a single tumor cell.

These tumors are not difficult to recognize. The tumor cells have an appearance resembling goblet cells or signet ring cells with mild cytological atypia. The cells form irregular, mostly small nonlumenized aggregates without the palisade arrangement of tumor cells near the stroma. There are no signs of desmoplasia around the tumor. Unlike "classical" carcinoids, they do not form solid tumor masses that are macroscopically visible. A striking feature is invasion of the tumor into all layers of the appendix. The entire thickness of the appendix wall is involved. The way the tumor spreads makes a pathologist suspect a primary lesion in another location such as in the cecum or elsewhere in the gastrointestinal tract. According to some authors 9 , tumors with a similar appearance may occur outside the appendix. However, some more recent studies show that tumors with an appearance similar to GCCs are rarely found in other locations. The prognosis is less favorable compared to "classical" G1 and G2 neuroendocrine tumors. In different cases, immunohistological examination results vary considerably. Frequently, neuroendocrine markers are positive in only small numbers of tumor cells or completely negative. To a large extent, pathological diagnosis relies on the special appearance and arrangement of tumor cells. Classification of these tumors remains a matter of discussion. The study aimed at comparing expression of neuroendocrine markers with expression of a marker of proliferation (Ki-67 proliferative index).

\section{MATERIALS AND METHODS}

In archives of the Department of Pathology, First Faculty of Medicine, Charles University and General University Hospital in Prague and the Department of Pathology, Faculty of Medicine, University of Ostrava and University Hospital in Ostrava, a total of nine cases were found that met the diagnostic criteria for GCC.

Immunohistological examination was carried out using the avidin-biotin complex (ABC) method. The following antibodies were used (working dilutions are given in parentheses): AE1-AE3 clone AE1-AE3 (1:50), Ck20 clone Ks 20.8 (prediluted), Ki-67 clone MIB-1 (1:50), Ck7 clone OU-TL 12/13 (1:50), NSE clone 2F11 (1:50), rabbit 
Table 1. Immunoprofile of GCC and adenocarcinoma ex GCC (Nos. 1, 4, 7).

\begin{tabular}{lccccccccc}
\hline Case & 1 & 2 & 3 & 4 & 5 & 6 & 7 & 8 & 9 \\
\hline Synapto & $30 \%$ & Neg. & $80 \%$ & $60 \%$ & $80 \%$ & $10 \%$ & $40 \%$ & $5 \%$ & Neg. \\
Chromo & Neg. & Neg. & $80 \%$ & $30-40 \%$ & $40-50 \%$ & Neg. & Neg. & Neg. & Neg. \\
CD56 & $50 \%$ & $5-10 \%$ & Neg. & $30-40 \%$ & $90 \%$ & $20 \%$ & $40 \%$ & Neg. & Neg. \\
NSE & $80 \%$ & $10 \%$ & $30 \%$ & $1 \%$ & $50 \%$ & $20 \%$ & $40 \%$ & Neg. & Neg. \\
Ck7 & $50 \%$ & $20 \%$ & $40 \%$ & $80 \%$ & $50 \%$ & $50 \%$ & $90 \%$ & $80 \%$ & Neg. \\
Ck20 & $80 \%$ & $80 \%$ & $80 \%$ & $80 \%$ & $90 \%$ & $90 \%$ & $80 \%$ & $90 \%$ & $90 \%$ \\
Ki-67 & $20 \%$ & $10-20 \%$ & $40 \%$ & $30 \%$ & $60-70 \%$ & $5 \%$ & $5-20 \%$ & $20-40 \%$ & $80 \%$ \\
CEA & $90 \%$ & $100 \%$ & $100 \%$ & $90 \%$ & $100 \%$ & $100 \%$ & $90 \%$ & $100 \%$ & $90 \%$ \\
AE1-AE3 & $100 \%$ & $100 \%$ & $90 \%$ & $90 \%$ & $100 \%$ & $100 \%$ & $100 \%$ & $90 \%$ & $100 \%$ \\
Somato & 0 & 0 & Neg. & Neg. & Neg. & Neg. & Neg. & 0 & Neg. \\
Sero & 0 & 0 & Neg. & $20 \%$ & $30 \%$ & Neg. & Neg. & 0 & Neg. \\
Gluca & 0 & 0 & 0 & 0 & Neg. & 0 & 0 & 0 & Neg. \\
E-cad & $100 \%$ & $80 \%$ & $80 \%$ & Neg. & $100 \%$ & 0 & 0 & $100 \%$ & $100 \%$ \\
P53 & Neg. & $10 \% \mathrm{C}$ & Neg. & Neg. & $80 \% \mathrm{C}$ & 0 & 0 & 0 & 0 \\
Beta-cat & $100 \%$ & $100 \%+/-$ & $100 \%$ & 0 & $100 \%$ & 0 & 0 & $100 \%$ & $100 \%$ \\
\hline
\end{tabular}

Legend: Synapto - synaptophysin; Chromo - chromogranin; Somato - somatostatin; Sero - serotonin; Gluca - glucagon; E-cad - E-cadherin; 0 - not performed; Neg. - negative; C - cytoplasmic positivity; beta-cat - beta-catenin

Table 2. Metastasis to lymph nodes and distant metastasis

Metastasis to lymph nodes

(the numbers refer to cases in Table 1)
Tumor spreading to the surrounding tissues and distant metastasis (the ovary, uterus and omentum)

$$
3,5,8
$$

anti-human somatostatin polyclonal antibody (1:1000), E-cadherin clone NCH-38 (1:50), beta-catenin clone betacatenin-1 (1:400) - all antibodies produced by DAKO, Glostrup, Denmark; synaptophysin clone 27G12 (1:100), chromogranin A clone $5 \mathrm{H} 7$ (1:100), CD56 clone 1B6 (1:50), p53 clone DO-7 (1:400) - all antibodies produced by Novocastra, Newcastle-upon-Tyne, UK; and CEA rabbit polyclonal antibody (1:50) - produced by Biogenex.

\section{RESULTS}

The unselected sample of nine patients comprised six females and three males; their ages ranged from 53 to 73 years. All patients were admitted and operated on for appendicitis. In six cases, hematoxylin and eosin staining revealed tumors completely or $90 \%$ made of characteristic GCC structures (Fig. 1). The remaining three cases (Table 1, Nos. 1,4,7) had a different histological pattern This was characterized by medium-sized cells with morphology different from that of goblet or signet ring cells. These formed trabecules, bands, tubules; alternatively, isolated tumor cells infiltrated the appendix wall. The nucleoplasmic ratio was in favor of the volume of the nucleus. The nuclei were of irregular shape in some areas, hyperchromatic and, sometimes, with distinct nucleoli. Large cells with mucin, characteristic for GCC, were found in $10-20 \%$ of tumor cells in these cases. Such tumors were identified as adenocarcinomas arising ex GCC (Fig. 2, $3,4)$.

Immunohistological examination revealed that in four cases, GCC-like tumor cells did not react with neuroendo- crine markers (in particular synaptophysin), either at all or in only a small proportion ( $5 \%$ and $10 \%$ of the cells) (Fig. 5a, 5b). Yet the Ki-67 proliferative index was positive in $10-20 \%$ of cells of one tumor (No. 2) and in $5 \%$ of cells of another tumor (No. 6). In the third (No. 8) and fourth (No. 9) cases, the rates were $20-40 \%$ and $80 \%$, respectively (Fig. 6). In the remaining cases, neuroendocrine markers and, especially, positivity against synaptophysin were demonstrated in as much as $80 \%$ of the cell population, with a high $\mathrm{Ki}-67$ proliferative index, ranging from $30 \%$ to $60 \%$ for individual patients. Positive results for an antibody against chromogranin were noted in only three cases. All tumors showed positive results with antibodies against cytokeratins AE1-AE3, CEA and cytokeratin 20. In eight cases, positivity with an antibody against $\mathrm{Ck} 7$ was observed. With an antibody against the p53 protein, the finding was negative. In two cases, cytoplasmic positivity was documented. Positive findings with an antibody against E-cadherin were seen in six out of seven cases. With an antibody against beta-catenin, positive findings were found in six out of six cases (Table 1).

Table 2 summarizes cases of metastasis to lymph nodes or local spread and distant metastasis to the ovary, uterus and omentum (the numbers refer to cases shown in Table 1).

\section{DISCUSSION}

GCC was first described in 1974 (ref. ${ }^{10}$ ). According to some authors ${ }^{3}$, it accounts for approximately $14 \%$ of all appendix tumors. In the WHO classification of carci- 


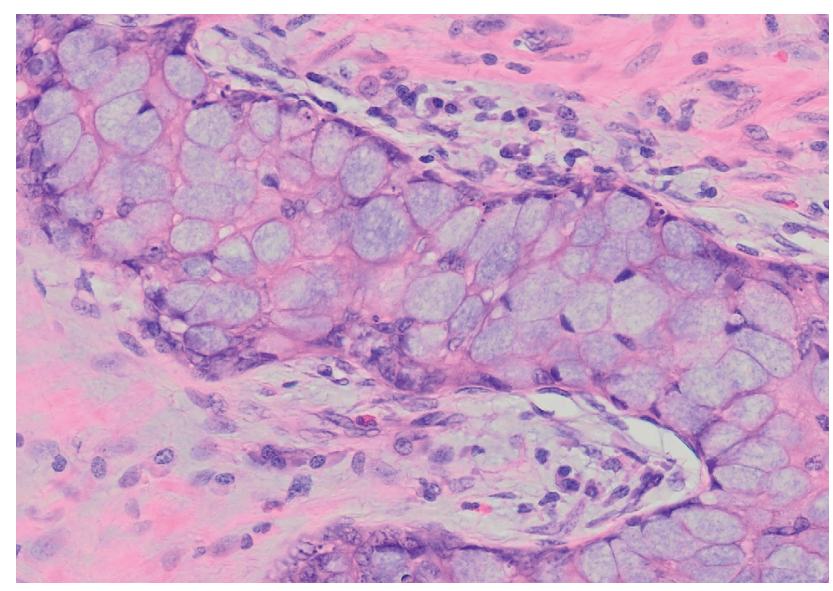

Fig. 1. Characteristic histological pattern of tumor cells with an appearance consistent with goblet cells or signet ring cells (HE, 200x).

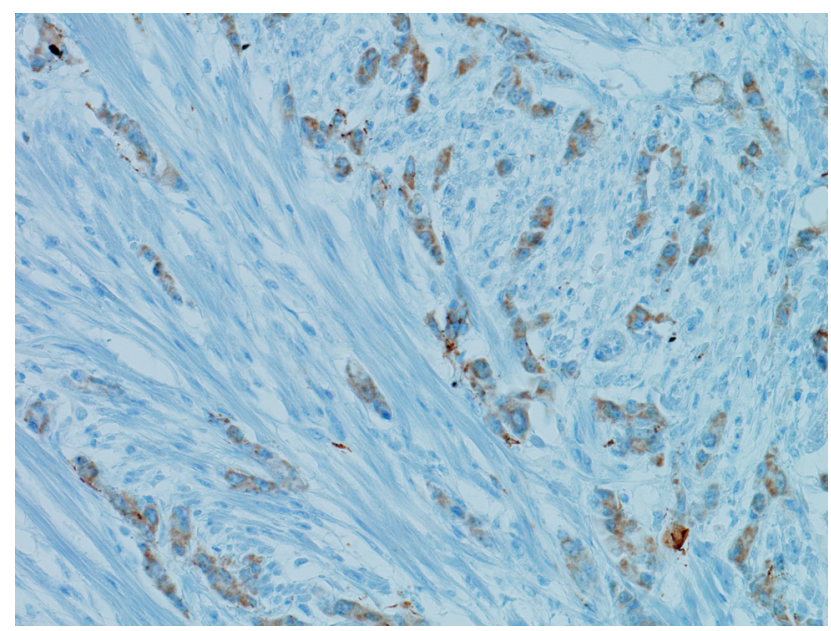

Fig. 3. Adenocarcinoma ex-goblet cell carcinoid cells are positive with a marker against synaptophysin (synaptophysin, 200x).

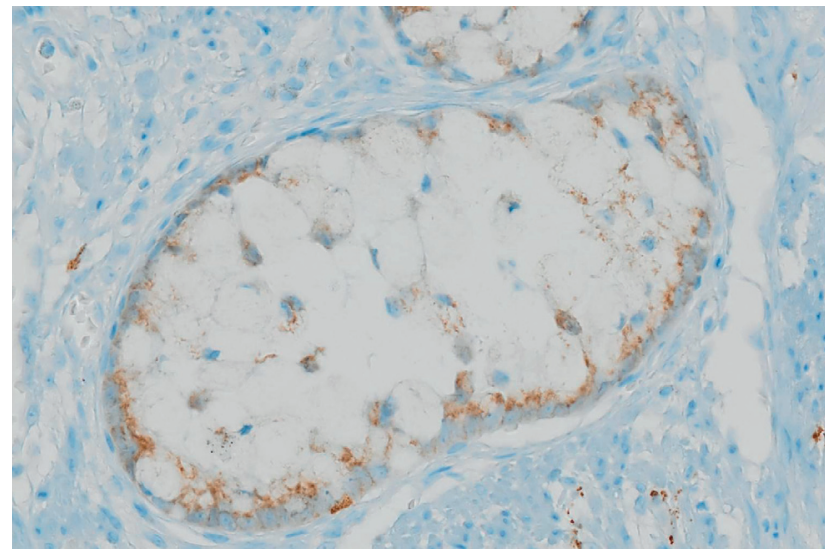

Fig. 5a. Comparison with a synaptophysin-positive focus of GCC (case No. 7) (synaptophysin, 200x).

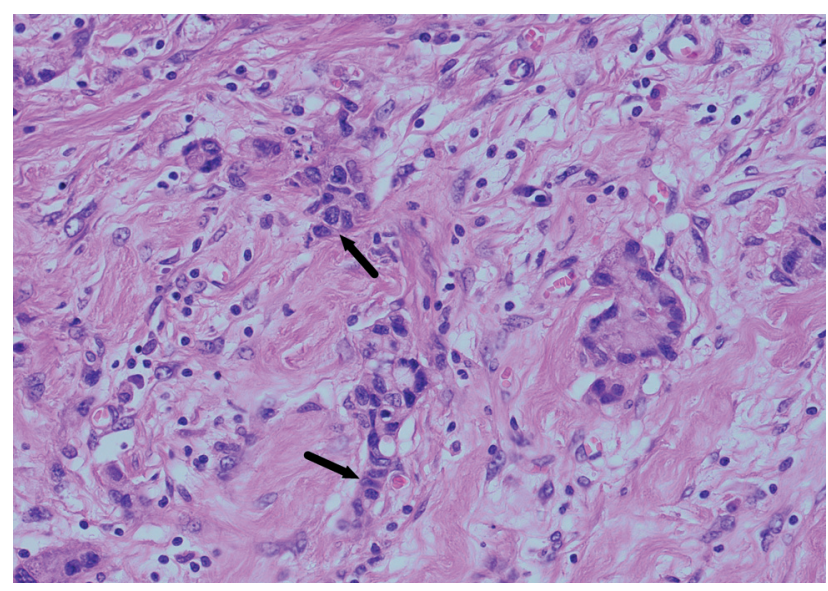

Fig. 2. Tumor GCC transforms into adenocarcinoma ex-goblet cell carcinoid (arrows point to adenocarcinoma cells) (HE, 200x).

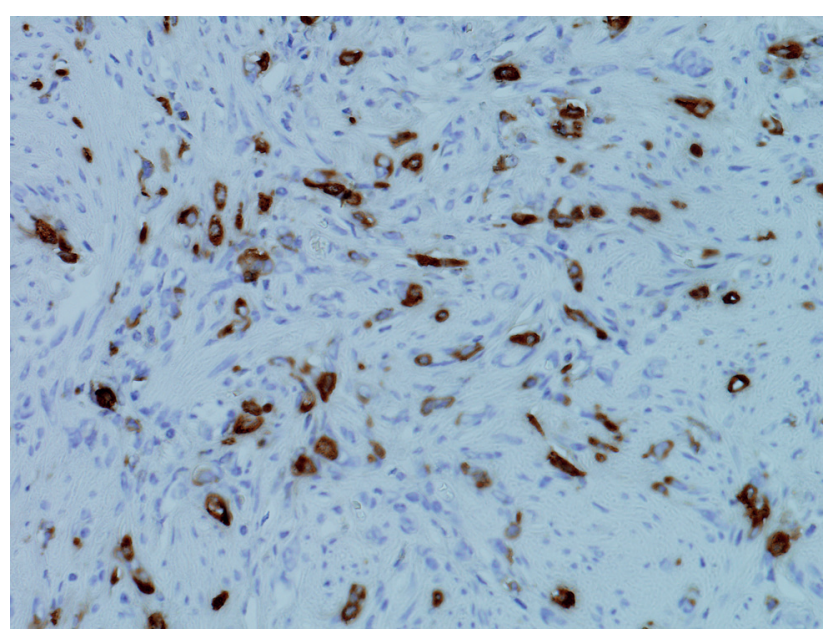

Fig. 4. Isolated cells of adenocarcinoma ex-goblet cell carcinoid positively react with an antibody against chromogranin (chromogranin, 200x).

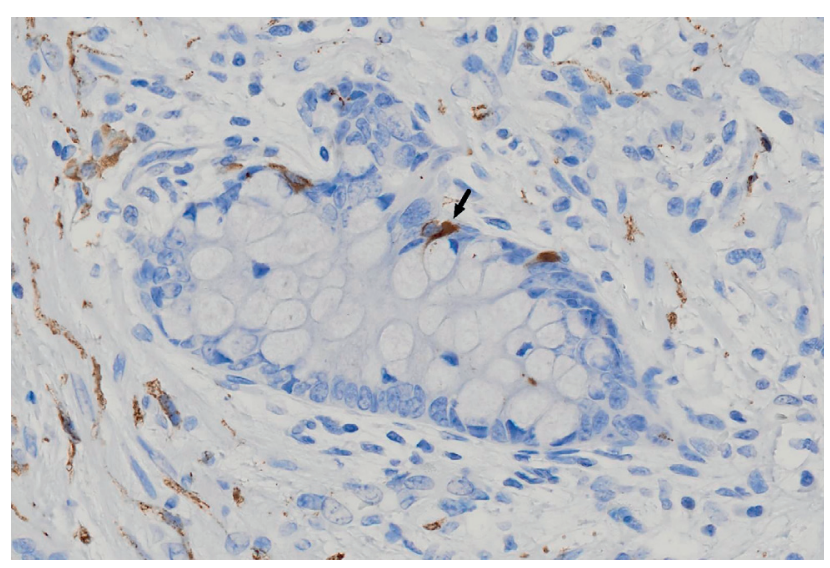

Fig. 5b. Immunohistological reaction with an antibody against synaptophysin. The tumor cells are negative. There are sparse non-tumor positive neuroendocrine cells (arrow) (synaptophy$\sin , 200 x)$. 


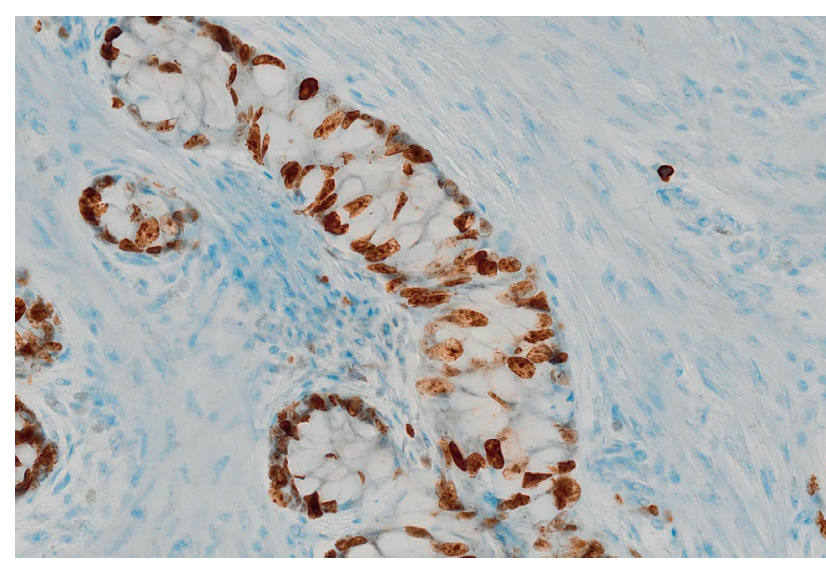

Fig. 6. Immunohistological reaction with the Ki-67 antibody. Significant positivity of most tumor cells (Ki-67, 200x).

noids, it is regarded as a separate entity and not as a variant of "classical" carcinoids of the appendix. Relatively frequently, GCC transforms into adenocarcinoma. This, together with other phenotypic and immunohistological characteristics distinguishing GCCs from "classical" carcinoids made some authors conclude that it is carcinoma from the very beginning. They referred to it as crypt cell carcinoma, microglandular goblet cell carcinoma or composite goblet cell carcinoid-adenocarcinoma ${ }^{1,11-14}$. GCC is histogenetically derived from pluripotent epithelial cells at the crypt base whereas "classical" carcinoids arise from subepithelial neuroendocrine cells originating from the neural crest ${ }^{12,15-18}$. The differences between the two types (both morphological and clinical) allowed for publication of a novel variant of neuroendocrine tumors of the appendix, namely combined classical carcinoid and GCC tumor ${ }^{15}$. GCC is characterized by production of neutral and acid glycosaminoglycans in the cytoplasm of tumor cells, demonstrated by the PAS method and alcian blue staining. At the same time, positive results are obtained by immunohistological examination with neuroendocrine markers such as synaptophysin, chromogranin and CD56. In some cases, however, positivity rates using these markers is relatively low or tumors are completely negative. According to some authors ${ }^{12}$, the diagnosis is more dependent on the morphological pattern than immunohistology results which, in rare cases, may be negative. The question arises as to which criteria should be applied to classify such tumors as neuroendocrine. In the present study, positivity rates with the Ki-67 proliferative index was considerably higher in two cases (Nos 8 and 9) than in G1 and G2 neuroendocrine tumors, ranging from $20 \%$ to $40 \%$ (No. 8 ) and reaching as much as $80 \%$ (No. 9). Even though the Ki-67 index is much higher than in "classical" carcinoids, an association between prognosis of the disease and the Ki-67 proliferative index has not been demonstrated as yet ${ }^{19,20}$. Tang et al. ${ }^{1}$ studied a sample of 63 GCC patients divided into three groups based on tumor cell differentiation. Only in the third group, including cases with poorly differentiated adenocarcinomas ex GCC, the Ki-67 positivity rates reached $80 \%$, as was the case in adenocarcinomas of the appendix. It means that there is a relationship between grading and positivity of the marker Ki-67. Higher Ki-67 positivity rates (> 10-20\%) are also observed in tumors that metastasize. Tumors with the Ki-67 below 5\% usually grow locally ${ }^{21}$. In the present study, two cases of typical GCC showed positivity rates well above $20 \%$, thus exceeding the range for G1 and G2 neuroendocrine tumors as defined by the current WHO criteria.

The results of immunohistological examination using the $\mathrm{Ki}-67$ proliferative index are not always reliable for assessment of the aggressive behavior of tumors. Pericleous et al. ${ }^{22}$ reported a case of GCC with lung metastasis and a $\mathrm{Ki}-67$ proliferative index of less than $5 \%$. In four cases of metastasis to lymph nodes and distant metastasis identified in the present study, the Ki-67 proliferative index ranged from $20 \%$ to $70 \%$.

A considerable number of cases of adenocarcinoma of the colon or appendix are associated with mutations in the genes for beta-catenin and p53. In the present study, p53 protein overexpression was not detected; intracytoplasmic positivity was observed in only two cases. Using an antibody against beta-catenin, positive findings were seen in six out of six cases. In one case, the intensity of staining was low. With an antibody against E-cadherin, positive findings were documented in six out of seven cases. Positive findings were seen in $80-100 \%$ of cells. In one case, the finding was negative. O'Dowd and Gosney ${ }^{23}$ failed to detect p53 protein overexpression in "classical" carcinoids in the gastrointestinal tract. Similar results were observed in GCC (ref. ${ }^{1}$ ).

So far, molecular genetic pathology results have shown genetic alterations compatible with GCC rather than with appendix tumors ${ }^{1,24-26}$. On the other side, van Eeden et al. ${ }^{27}$ used 21 immunohistological markers in their study and found expression of the transcription factors Math1 and HD5 in GCC and adenocarcinomas but not in "classical" carcinoids. The authors inferred that GCC and adenocarcinomas of the appendix have more common features than "classical" carcinoids. The marker CEA, positive in colon adenocarcinoma, was significantly positive in all cases in the present study. It tends to be negative in "classical" carcinoids. We assume that cases with negative or very little positive ( $<10 \%$ positivity) neuroendocrine markers and highly positive findings with Ki-67 should be identified as a special group referred to as a specific type of carcinoma by van Eeden et al. ${ }^{27}$.

\section{CONCLUSION}

GCC of the appendix continue to be included among neuroendocrine tumors in the WHO classification, even though, in some cases, expression of neuroendocrine markers is low or completely absent. Yet the Ki-67 proliferative index exceeds values set for G1 and G2 neuroendocrine tumors. Patients with these tumors have a poorer prognosis than those with "classical" G1 and G2 neuroendocrine tumors. GCCs seem to be a heterogeneous group of tumors with an identical phenotype but different immunohistological profiles. It is our opinion 
that such tumors should be classified as a specific type of carcinoma, as suggested by van Eeden et al. ${ }^{27}$.

Author contribution: All authors contributed equally to preparing the manuscript.

Conflict of interest statement: The authors state that there are no conflicts of interest regarding the publication of this article.

\section{REFERENCES}

1. Tang LH, Shia J, Soslow RA, Dhall D, Wong WD, O'Reilly E, Qin J, Paty P, Weiser MR, Guillem J, Temple L, Sobin LH, Klimstra DS. Pathologic classification and clinical behavior of the spectrum of goblet cel carcinoid tumors of the appendix. Am J Surg Pathol 2008;32:142943.

2. Lin BT, Gown AM. Mixed carcinoid and adenocarcinoma of the appendix: report of 4 cases with immunohistochemical studies and a review of the literature. Appl Immunohistochem Mol Morpho 2004;12:271-6.

3. McCusker ME, Cote TR, Clegg LX, Sobin LH. Primary malignant neoplasms of the appendix: a population-based study from the surveillance, epidemiology and end-results program, 1973-1998. Cancer 2002;94:3307-12.

4. Dockerty MB, Ashburn FS. Carcinoid tumors (so-called) of the ileum report of thirteen cases in which there was metastasis. Arch Surg 1943;47:221-46.

5. Horn RC Jr. Carcinoid tumors of the colon and rectum. Cancer 1949;2:819-37.

6. Lattes R, Grossi C. Carcinoid tumors of the stomach. Cancer 1956;9:698-711.

7. Gagné F, Fortin P, Dufour V, Delage C. Tumeurs de I'appendice associate des caractères histologiques de carcinoide et d'adénocarcinome. Ann Anat Pathol 1969;14:393-406.

8. Höfler H, Klöppel G, Heitz PU. Combined production of mucus, amines and peptides by goblet-cell carcinoids of the appendix and ileum. Path Res Pract 1984;178:555-61.

9. Watson PH, Alguacil-Garcia A. Mixed crypt cell carcinoma. A clinicopathological study of the so-called "goblet cell carcinoid". Virchows Archiv A 1987:412:175-82.

10. Subbuswamy SG, Gibbs NM, Ross CF, Morson BC. Goblet cell carcinoid of the appendix. Cancer 1974;34:338-44.

11. Carr NJ, Sobin LH. Neuroendocrine tumors of the appendix. Semin Diag Pathol 2004;21:108-19.

12. Gui X, Quin L, Gao ZH, Falck V, Harpaz N. Goblet cell carcinoids at extraappendiceal locations of gastrointestinal tract: an underrecognized diagnostic pitfall. J Surg Oncol 2011;103:790-5.
13. Kanthan R, Saxena A, Kanthan SC. Goblet cell carcinoids of the appendix: immunophenotype and ultrastructural study. Arch Pathol Lab Med 2001;125:386-90.

14. Edmons P, Merino MJ, LiVolsi V, Duray PH. Adenocarcinoid (mucinous carcinoid) of the appendix. Gastroenterology 1984;86:302-9.

15. Chetty R, Klimstra DS, Henson DE, Albores-Saavedra J. Combined classical carcinoid and goblet cell carcinoid tumor: A new morphological variant of carcinoid tumor of the appendix. Am J Surg Pathol 2010;34:1163-7.

16. Reid DM, Bastruk O, Shaib WL, Xue Y, Balci S, Choi HJ, Akkas G, Memis B, Robinson BS, El-Rayes BF, Staley CA, Staley CA, Winer $\mathrm{JH}$, Russell MC, Knight JH, Goodman M, Krasinskas AM, Adsay V. Adenocarcinoma ex-goblet carcinoid (appendiceal-type crypt cell adenocarcinoma) is a morphologically distinct entity with highly aggressive behavior and frequent association with peritoneal/ intra-abdominal dissemination: an analysis of 77 cases. Mod Pathol 2016;00:1-11. doi:10.1038 modpathol.2016.105

17. Gallegos NC, Milroy C, Linehan IP, Boulos PB. Crypt cell carcinoma of the appendix. Eur J Surg Oncol 1992;18:386-7.

18. Isaacson P. Crypt cell carcinoma of the appendix (so-called adenocarcinoma tumor). Am J Surg Pathol 1981;5:213-24.

19. Liu E, Telem DA, Warner RR, Dikman A, Divino M. The role of Ki-67 in predicting biological behavior of goblet cell carcinoid tumor in appendix. Am J Surg 2011;202:400-3.

20. Holt N, Grønbaek H. Goblet cell carcinoids of the appendix. Scientific World Journal 2013;2013:543696. doi:10.1155/2013/543696

21. Toumpanakis C, Standish RA, Baiehnab MC, Winslet MC, Caplin ME. Goblet cell carcinoid tumors (adenocarcinoid) of the appendix. Dis Colon Rectum 2007;50:315-22.

22. Pericleous $M$, Lumgair $H$, Baneke A, Morgan-Rowe L, Caplin ME, Luong TV, Thrilwell C, Gillmore R, Toumpanakis C. Appendiceal goblet cell carcinoid tumour: a case of unexpected lung metastasis. Case Rep Oncol 2012; 5:332-8.

23. O'Dowd G, Gosney JR. Absence of overexpression of $\mathrm{p} 53$ protein by intestinal carcinoid tumours. J Pathol 1995;175:403-4.

24. Kabbani W, Houlihan PS, Luthra R, Hamilton SR, Rashid A. Mucinous and nonmucinous appendiceal adenocarcinomas: different clinicopathological features but similar genetic alterations. Mod Pathol 2002;15:599-605.

25. Ramnani DM, Wistuba II, Behrens C, Gazdar AF, Sobin LH, AlboresSaavedra J. K-ras and p53 mutations in the pathogenesis of classical and goblet cell carcinoids of the appendix. Cancer 1999:86:14-21.

26. Stancu M, Wu TT, Wallace C, Houlihan PS, Hamilton SR, Rashid A. Genetic alterations in goblet cell carcinoids of the vermiform appendix and comparison with gastrointestinal carcinoid tumors. Mod Pathol 2003;16:1189-98.

27. van Eeden S, Offerhaus GJA, Hart AA, Boerrigter L, Nederlof PM, Porter E, Velthuysen von M-LF. Goblet cell carcinoid of the appendix: a specific type of carcinoma. Histopathology 2007;51:763-73. 